\title{
Linking farm management and ecosystem service provision: Challenges and opportunities for soil erosion prevention in Mediterranean silvo-pastoral systems
}

\author{
Carlos A. Guerra, Teresa Pinto-Correia
}

Abstract: At both local and landscape levels, farm management is the main driver of land cover change influencing ecosystem functions, processes and traits. In Mediterranean large-scale silvo-pastoral systems these changes can have serious implications in the provision of valuable ecosystem services (ES). Current ES assessment, mapping and valuation are still focused in representing the state and trends of ES provision, often missing the link to actual farm management and farm management systems. We propose an approach that, at the farm level, combines the classification of farm management systems with indicators of ES provision. This is illustrated for soil erosion prevention, a key ES in mitigating current and future impacts in Mediterranean regions and the proposed approach is tested in Southern Portugal. We characterize thirty-eight large-scale farm management units (FMU) regarding their management system and environmental traits. Each FMU was then classified according to their management system and a set of ES indicators was calculated. To classify the FMU, data on livestock composition and grazing density, pastures, and soil mobilization practices were object of a cluster analysis and the result was tested against a set of ES indicators. The results highlight the implications and challenges for the provision of soil erosion prevention under different farm management systems and draw a clear relation between more intensive management practices and the degradation of service provision. Our results can also be used to support land management and policy design through the definition of intensity thresholds that consider the local environmental and ecological conditions

Keywords: Decision support; Montado; Regulating services; Farm manager; Farm system; Erosion

Doi: doi:10.1016/j.landusepol.2015.10.028

Citação: Guerra, C.A., Pinto-Correia, T., 2016, Linking farm management and ecosystem service provision: Challenges and opportunities for soil erosion prevention in Mediterranean silvo-pastoral systems. Land Use Policy Volume 51, February 2016, Pages 54-65. doi:10.1016/j.landusepol.2015.10.028 